\title{
ACÚMULO E EXPORTAÇ̃̃O DE MICRONUTRIENTES EM UM POVOAMENTO DE ACÁCIA-NEGRA (Acacia mearnsii DE WILD.) PROCEDÊNCIA BODALLA - AUSTRÁLIA
}

\author{
Marcos Vinicius Winckler Caldeira ${ }^{1}$ \\ Rubens Marques Rondon Neto \\ Mauro Valdir Schumacher
}

\begin{abstract}
RESUMO
O presente trabalho teve por objetivo avaliar o conteúdo e a exportação de micronutrientes ( $\mathrm{Mn}, \mathrm{B}, \mathrm{Cu}, \mathrm{Zn}$ e $\mathrm{Fe}$ ) e Na nos diferentes componentes das árvores de um povoamento de acácia-negra (Acacia mearnsii De Wild.), procedência australiana Bodalla, com 2,4 anos de idade no município de Butiá/RS. A proporção de micronutrientes acumulada na biomassa acima do solo dos componentes da árvore foi: folhas (46,8\%), galhos vivos $(19,7 \%)$, casca $(12,1 \%)$, galhos mortos $(12,0 \%)$ e madeira do tronco $(9,4 \%)$. A quantidade estimada de micronutrientes contido na biomassa acima do solo foi de $5,2 \mathrm{~kg}$ ha-1.

Palavras chave: Acacia mearnsii, acácia-negra, micronutrientes, exportação de micronutrientes
\end{abstract}

\section{ACCUMULATION AND MICRONUTRIENT EXPORTATION OF IN A STAND OF BLACK WATTLE (Acacia mearnsii DE WILD.) AUSTRALIAN BODALLA PROCEDENCE}

\begin{abstract}
The present study had the purpose of evaluating the micronutrient ( $\mathrm{Mn}, \mathrm{B}, \mathrm{Cu}, \mathrm{Zn}$ e $\mathrm{Fe}$ ) and $\mathrm{Na}$ content in exportation in diferent components of the 2.4 year old black wattle (Acacia mearnsii De Wild.), trees from Bodalla Australian provenance in the municipality of Butiá/RS. 46.8\% of the nutrients accumulated inn the leaves, $19.7 \%$ in the live branches, $12.0 \%$ in the dead branchesa nd $9.4 \%$ in the wood of the stem. The estimated micronutrient content in the above-ground biomass was $5,2 \mathrm{~kg}$ ha- 1 .
\end{abstract}

Key-words: Acacia mearnsii, black wattle, micronutrients, micronutrients of exportation

\section{INTRODUÇÃO}

No Brasil, a acácia-negra (Acacia mearnsii De Wild.) é plantada com fins comerciais principalmente no Estado do Rio Grande do Sul cobrindo cerca de 100.000 hectares. A maioria dessas plantações encontra-se em pequenas propriedades rurais, com participação de mais de 10.000 produtores (Higa et al., 1998). A madeira é utilizada na fabricação de celulose, aglomerado e energia, da casca é extraído o tanino, empregado na indústria farmacêutica, e coureira entre outras.

A maioria dos povoamentos de acácianegra são implantados em solos com baixos níveis de fertilidade e as práticas de manejo normalmente são realizadas de forma incorreta. Sob tais condições, os índices de produtividade normalmente são baixos sendo, portanto indispensável a adoção de práticas de manejo do solo florestal a fim de elevar os níveis de fertilidade e produtividade dos sítios (Dallago, 2000).

A quantidade de nutrientes contida na copa (folha e galhos), casca, serapilheira e os resíduos culturais, representam uma porção significativa do estoque de nutrientes do povoamento florestal, que pode ser utilizado nas rotações futuras. Portanto, o conhecimento da distribuição dos nutrientes nos componentes das árvores é fundamental para estudar a nutrição, reciclagem e exportação de nutrientes.

Dentro desse contexto, alguns trabalhos já foram realizados (Vezzan, 1997; Pereira et al., 1999; 2000; Caldeira et al.,

${ }^{1}$ Prof. FURB/. caldeira@furb.br

Eng ${ }^{\text {}}$. Florestal, Dr. Prof. /UFSM

Recebido para publicação: 05/07/2001

Aceito para publicação: 25/07/2002 
1999a; 1999b; 1999c; 2000). Entretanto, no que diz respeito a concentração e exportação de micronutrientes em acácia-negra, poucos trabalhos foram realizados até então.

O presente trabalho teve como objetivo avaliar o acúmulo e a exportação de micronutrientes em um povoamento de acácianegra, procedência australiana Bodalla, com 2,4 anos de idade, no município de Butiá/RS.

\section{MATERIAIS E MÉTODOS}

O presente trabalho foi realizado em um povoamento de acácia-negra, com 2,4 anos de idade e plantado no espaçamento $1,7 \times 3,0$ $\mathrm{m}$, localizado na região fisionômica natural do Estado do Rio Grande do Sul denominada Serra do Sudeste (Escudo Rio-grandense), município de Butiá - RS. Tal maciço florestal, situa-se entre as coordenadas geográficas $30^{\circ}$ 07'12" S e $51^{\circ} 57^{\prime} 45^{\prime \prime}$ W e a uma altitude média de 35 metros.

Pelo sistema de classificação de Koeppen o clima da região é do tipo Cfa, subtropical (Moreno, 1961). A temperatura média anual desta região é de $18-19^{\circ} \mathrm{C}$, com temperaturas médias máximas e mínimas no ano de 24 e $14^{\circ} \mathrm{C}$, respectivamente. A precipitação média anual é de $1.400 \mathrm{~mm}$ (IPAGRO, 1989).

$\mathrm{O}$ solo da região pertence à Unidade de Mapeamento São Jerônimo, classificado como Argissolo Vermelho Escuro (EMBRAPA, 1999). Os solos dessa Unidade são em geral profundos, bem drenados, franco argiloso ou argiloso com cascalho, porosos e desenvolvidos a partir de granito. São também fortemente ácidos, com baixa saturação e soma de bases e teores baixos de matéria orgânica (BRASIL, 1973).

Para a quantificação do conteúdo de micronutrientes na biomassa acima do solo da acácia-negra selecionou-se nove árvores, procedentes de Bodalla, New South Wales, Austrália $\left(36^{\circ} 11^{\prime} \mathrm{S}\right.$ e $149^{\circ} 58^{\prime}$ E e altitude de $15 \mathrm{~m}$ s.n.m.). Na parte intermediária da copa das árvores, nos quatro pontos cardeais, foram coletadas folhas para a realização de análise nutricional. Os galhos foram classificados como vivos e mortos, desse primeiro todas as folhas foram colhidas.

A massa fresca total das folhas, galhos vivos e mortos, casca e madeira do tronco de todas as árvores foram determinadas no campo. De cada um desses componentes retirou-se amostras para aferição da massa fresca no campo. Posteriormente, cada componente foi acondicionado em sacos plásticos identificados e levados ao Laboratório de Ecologia Florestal do Departamento de Ciências Florestais da Universidade Federal de Santa Maria, onde foram embalados em sacos de papel pardo e colocados em estufa com circulação forçada $\left(75^{\circ} \mathrm{C}\right)$, até atingirem peso constante.

A madeira do tronco foi amostrada em um disco de 5,0 cm de espessura por árvore, retirado na metade da altura total da árvore (Yong \& Carpenter, 1976). Desse disco, separou-se casca e madeira e foi registrado a massa fresca de cada componente. Após a secagem em estufa, as amostras desses dois componentes foram picadas para facilitar a moagem. As amostras das demais frações vegetais (folhas, galho vivo e morto) foram moídas em moinho do tipo Wiley e passadas em peneira com malha de $1,0 \mathrm{~mm}$. Depois que todos os componentes da árvore foram moídos, retirou-se uma alíquota de cada amostra que foram enviadas ao laboratório para a realização das análises.

Para as determinações das concentrações dos micronutrientes (manganês, boro, cobre, zinco e ferro) e sódio seguiu-se as metodologias propostas por Tedesco et al. (1995). As análises foram realizadas no Laboratório de Análise de Solos do Departamento de Solos da Faculdade de Agronomia da Universidade Federal do Rio Grande do Sul.

$\mathrm{O}$ estoque de micronutrientes em todos os componentes da biomassa acima do solo em $\mathrm{kg} \cdot \mathrm{ha}^{-1}$, foi obtido a partir da biomassa determinada por Caldeira (1998) e da concentração dos micronutrientes. A soma dos valores dos micronutrientes para cada componente da biomassa acima do solo forneceu o conteúdo total em kg.ha ${ }^{-1}$ dos mesmos.

\section{RESULTADOS E DISCUSSÃO}

A tab. 1 mostra os resultados do conteúdo e quantidade média dos micronutrientes acumulados em cada componente da biomassa acima do solo. Pode- 
se observar que $46,8 \%$ dos micronutrientes acumulam nas folhas, $19,7 \%$ nos galhos vivos, $12,1 \%$ na casca, $12,0 \%$ nos galhos mortos e $9,4 \%$ no lenho da madeira. Portanto, na copa (folhas, galhos vivos e mortos) concentra-se $78,5 \%$ do total de micronutrientes que se acumularam na biomassa acima do solo. Resultados diferentes foram obtidos por Poggiani et al. (1983), em um povoamento de Eucalyptus grandis Hill ex-Maiden com 2,5 anos de idade, onde verificaram que do total de micronutrientes analisados $(\mathrm{Cu}, \mathrm{Fe}, \mathrm{Mn}, \mathrm{Zn})$, $23 \%$ se concentravam nas folhas; $6,8 \%$ nos galhos; $29,91 \%$ na copa e $40,16 \%$ na madeira.

Nas folhas, encontra-se a maioria das células vivas da árvore, que tendem a acumular maiores quantidades de nutrientes, em função dos processos de transpiração e fotossíntese (Kramer \& Kozlowski, 1979). Ao comparar os acúmulos de $\mathrm{Cu}, \mathrm{Fe}, \mathrm{Mn}$ e $\mathrm{Zn}$ nas folhas da acácia-negra do presente trabalho com os resultados obtidos por Bellote et al. (2000), em um povoamento de acácia-negra com 3 anos de idade, observa-se pequenas diferenças nos resultados. O acúmulo de nutrientes na planta varia consideravelmente com a espécie, procedência, idade, posição das folhas, época do ano, sítio e concentração do nutriente no solo (Van Den Driessche, 1984; Koehler, 1989; Bellote, 1990).

A estimativa do estoque de micronutrientes e $\mathrm{Na}$ em todos os componentes da biomassa acima do solo é de $5,2 \mathrm{~kg} \mathrm{ha}^{-1}$. Desse total, tem-se a seguinte contribuição de cada nutriente analisado na biomassa: $\mathrm{Na}$ $(55,10 \%), \quad \mathrm{Fe}(24,30 \%), \mathrm{Zn} \quad(7,30 \%), \mathrm{Mn}$ $(7,60 \%)$, B $(4,20 \%)$ e $\mathrm{Cu}(1,60 \%)$. Baggio (1994), em florestas naturais de bracatinga (Mimosa scabrella Benth.), obteve uma produção média de $10,1 \mathrm{~kg} \mathrm{ha}^{-1}$, com a respectiva contribuição dos nutrientes: $\mathrm{Mn}$ $(55,7 \%), \mathrm{Fe}(34,7 \%), \mathrm{Zn}(2,6 \%)$ e $\mathrm{Cu}(2,1 \%)$, portanto, observa-se semelhança na proporção de acúmulo de nutrientes entre as duas leguminosas.

Tabela 1: Conteúdo e quantidade média de micronutrientes e Na nos diferentes componentes da biomassa acima do solo da acácia-negra (Acacia mearnsii De Wild.) procedência australiana Bodalla, com 2,4 anos de idade no município de Butiá/RS

Table 1: Contents and average amount of micronutrients and Na in the different components of above-ground biomass of black wattle (Acacia mearnsii De Wild.) from Australian Bodalla provenance, 2.4 years old in the municipality of Butiá/ RS

\begin{tabular}{|c|c|c|c|c|c|c|c|c|c|c|c|c|}
\hline \multirow[t]{3}{*}{ Comp. } & \multicolumn{12}{|c|}{ Nutrientes } \\
\hline & \multicolumn{2}{|c|}{$\mathrm{Mn}$} & \multicolumn{2}{|c|}{$\mathrm{Na}$} & \multicolumn{2}{|c|}{ B } & \multicolumn{2}{|c|}{$\mathrm{Cu}$} & \multicolumn{2}{|c|}{$\mathrm{Zn}$} & \multicolumn{2}{|c|}{$\mathrm{Fe}$} \\
\hline & $\mathrm{mg} / \mathrm{kg}$ & $\mathrm{kg} / \mathrm{ha}$ & $\mathrm{mg} / \mathrm{kg}$ & $\mathrm{kg} / \mathrm{ha}$ & $\mathrm{mg} / \mathrm{kg}$ & $\mathrm{kg} / \mathrm{ha}$ & $\mathrm{mg} / \mathrm{kg}$ & $\mathrm{kg} / \mathrm{ha}$ & $\mathrm{mg} / \mathrm{kg}$ & $\mathrm{kg} / \mathrm{ha}$ & $\mathrm{mg} / \mathrm{kg}$ & $\mathrm{kg} / \mathrm{ha}$ \\
\hline Folhas & 49,56 & 0,217 & 354,33 & 1,551 & 12,56 & 0,055 & 8,17 & 0,036 & 50,78 & 0,222 & 139,89 & 0,612 \\
\hline $\begin{array}{c}\text { Galhos } \\
\text { vivos }\end{array}$ & 10,41 & 0,040 & 153,44 & 0,591 & 11,78 & 0,045 & 4,28 & 0,016 & 16,67 & 0,064 & 62,44 & 0,240 \\
\hline $\begin{array}{l}\text { Galhos } \\
\text { mortos }\end{array}$ & 11,49 & 0,001 & 91,33 & 0,007 & 8,00 & 0,0006 & 3,17 & 0,0002 & 8,68 & 0,0006 & 35,33 & 0,003 \\
\hline Casca & 16,44 & 0,040 & 47,11 & 0,114 & 18,44 & 0,045 & 2,23 & 0,005 & 12,16 & 0,029 & 62,89 & 0,152 \\
\hline Madeira & 11,43 & 0,100 & 78,00 & 0,683 & 4,67 & 0,041 & 2,89 & 0,025 & 7,29 & 0,064 & 19,00 & 0,166 \\
\hline Total & $33,23^{*}$ & 0,398 & $258,0 *$ & 2,946 & $16,5^{*}$ & 0,187 & $6,92 *$ & 0,082 & $34,1^{*}$ & 0,380 & $109,0 *$ & 1,173 \\
\hline
\end{tabular}

*Valores médios 
A casca e a madeira do lenho são os componentes das árvores extraídos das florestas de acácia-negra. Ambos acumularam $21,0 \%$ do total de micronutrientes, então, caso o povoamento fosse explorado nessa idade, cerca de $1,464 \mathrm{~kg} \mathrm{ha}^{-1}$ de nutrientes seriam exportados. Entretanto, deve-se lembrar que a rotação da acácia-negra ocorre entre 7 e 9 anos. Conforme Lima (1996) o corte das árvores mais jovens pode, genericamente, remover mais nutrientes do que o corte a idades mais avançada. Nesse contexto, a remoção dos nutrientes para fora do sítio mediante a colheita de madeira com casca está fortemente relacionada com a idade das árvores e com o teor dos nutrientes nos componentes da biomassa acima do solo. A casca e a madeira do lenho da acácia-negra apresentam a seguinte participação percentual sobre o conteúdo total de micronutrientes acumulados nas árvores: $\mathrm{B}$ (46,1\%), $\mathrm{Cu}$ $(36,5 \%), \mathrm{Mn}(35,2 \%), \mathrm{Fe}(27,1 \%), \mathrm{Na}(27,0 \%)$ e $\mathrm{Zn}(24,5 \%)$.

Em valores absolutos o $\mathrm{Na}$ e o $\mathrm{Fe}$ são os elementos que mais se acumularam na casca e no lenho $\left(0,797\right.$ e $0,318 \quad \mathrm{~kg} \mathrm{ha}^{-1}$, respectivamente) seguindo-se o $\mathrm{Mn}(0,140 \mathrm{~kg}$ $\left.\mathrm{ha}^{-1}\right)$, o B $\left(0,086 \mathrm{~kg} \mathrm{ha}^{-1}\right)$, o Cu $\left(0,300 \mathrm{~kg} \mathrm{ha}^{-1}\right) \mathrm{e}$ o Zn $\left(0,093 \mathrm{~kg} \mathrm{ha}^{-1}\right)$.

A elevada contribuição do $\mathrm{Na}$ em relação aos demais nutrientes pode ser em função na sua diferença de capacidade de absorção deste elemento das raízes e na translocação para as partes novas da planta, sendo que substancialmente isso difere entre genótipos de uma mesma espécie (Marschner, 1997). A alta absorção de Na por acácia-negra pode ser em função de que este elemento está sendo absorvido no lugar do $\mathrm{K}$, mas isso precisa ser mais estudado. Isso também foi observado em Acacia mearnsii procedência Batemans Bay (Caldeira et al., 2002). Neste sentido, foi observado que as procedências de acácia-negra Batemans Bay e Bodalla seguido do $\mathrm{N}$ possuem as maiores quantidades de $\mathrm{K}$ na biomassa acima do solo (Caldeira et al., 2000; 2001).

O papel do Na na nutrição mineral de plantas tem a função de substituir o $\mathrm{K}$ em determinadas funções fisiológicas, tais como: funções específicas no meristema, na expansão de tecidos e células, no balanço de água das plantas e no aumento do número de estômatos por unidade de área. Em determinadas espécies $95 \%$ do $\mathrm{K}$ presente no substrato pode ser substituído por $\mathrm{Na}$ (Marschner, 1997).

A estimativa da quantidade de micronutrientes acumulados na copa (folhas e galhos vivos e mortos) foi $3,7 \mathrm{~kg} \mathrm{ha}^{-1}$. Portanto, supondo um sistema de colheita florestal que deixasse no sítio as folhas e os galhos vivos e mortos, cerca de $78,5 \%$ do total de micronutrientes acumulados permaneceriam no sítio. A participação percentual sobre o total de nutrientes acumulados na árvore e presentes na copa é a seguinte: $\mathrm{Zn}(75,5 \%), \mathrm{Fe}(72,9 \%), \mathrm{Na}$ (72,9\%), Mn (64,8\%), Cu (63,5\%) e B $(53,9 \%)$. O Na e o Fe foram os nutrientes que apresentaram maior quantidade na copa $(2,142$ e $0,852 \mathrm{~kg} \mathrm{ha}^{-1}$, respectivamente) seguido pelo Zn $\left(0,286 \mathrm{~kg} \mathrm{ha}^{-1}\right)$, Mn $\left(0,257 \mathrm{~kg} \mathrm{ha}^{-1}\right)$, B $\left(0,100 \mathrm{~kg} \mathrm{ha}^{-1}\right)$ e $\mathrm{Cu}\left(0,052 \mathrm{~kg} \mathrm{ha}^{-1}\right)$.

Conteúdos superiores de micronutrientes acumulados na copa (acículas e galhos) de Pinus taeda L., com 7 anos idade foram observados por Valeri et al. (1989), que estimou $6,01 \mathrm{~kg} \cdot \mathrm{ha}^{-1}$ de micronutrientes, com a contribuição dos nutrientes: $\mathrm{Mn}\left(3,57 \mathrm{~kg} \mathrm{ha}^{-1}\right)$, Fe $\left(1,72 \mathrm{~kg} \mathrm{ha}^{-1}\right), \mathrm{B}\left(0,29 \mathrm{~kg} \mathrm{ha}^{-1}\right), \mathrm{Zn}(0,27 \mathrm{~kg}$ $\left.\mathrm{ha}^{-1}\right)$ e $\mathrm{Cu}\left(0,15 \mathrm{~kg} \mathrm{ha}^{-1}\right)$.

O elevado conteúdo de micronutrientes na copa, torna esse componente vegetal muito importante na ciclagem de nutrientes, embora neste caso represente pequena porção da biomassa total $(42,6 \%)$. Durante a fase jovem de um povoamento, a alocação dos carboidratos é resultante da fotossíntese, os quais são canalizados para a biomassa da copa. Com o passar do tempo, quando as copas começam a competir entre si, a produção relativa de biomassa do o tronco aumenta e a das folhas e ramos diminui gradativamente (Reis \& Barros, 1990). Portanto, a adoção de sistemas de colheita florestal que deixe no sítio a copa das árvores, poderá contribuir em parte com o fornecimento de micronutrientes para as rotações subseqüentes.

\section{CONCLUSÕES}

Através dos resultados do presente estudo pode-se concluir que $78,52 \%$ do total de micronutrientes acumulados na biomassa acima do solo da acácia-negra encontram-se concentrados na copa (folhas e galhos verdes e 
mortos), apesar de representar 42,63\% da biomassa total das árvores.

\section{AGRADECIMENTOS}

Os autores manifestam seus agradecimentos ao Eng. Florestal Elias Moreira dos Santos da Empresa Florestal Agroseta S/A pela indispensável colaboração nas atividades de campo.

\section{REFERÊNCIAS}

BAGGIO, A. J. Estudio sobre el sistema agroforestal tradicional de la bracatinga (Mimosa scabrella Benth.) en Brasil productividad, manejo de residuos $y$ elaboracion de compost. Madrid: Escuela Tecnica Superior de Ingenieros de Montes, 1994. 242 p. (Tese - Doutorado).

BELlOTE, A. F. J. Suprimento de nutrientes minerais e crescimento de plantações adubadas de Eucalyptus grandis nos cerrados do Estado de São Paulo. Fraiburg: Universidade de Fraiburg. 1990. 166 p. (Tese de Doutorado).

BELlOTE, A. F. J.; SARRUGE, J. R.; HAAG, H. P.; OLIVEIRA, G. D. de. Extração e exportação de nutrientes pelo Eucalyptus grandis Hill ex-Maiden em função da idade: 2 - micronutrientes. IPEF. Piracicaba: n.20, p. 27-45, 1980.

BELlOTE, A. F. J.; SILVA, H. D. da; DEDECEK, R. A. Teores de macro e micronutrientes em acácia-negra, com três anos de idade, plantada no Estado do Rio Grande do Sul: In: FertBio 2000 Biodinâmica do Solo; Reunião Brasileira de fertilidade do solo e nutrição de plantas, 24, 2000; Reunião Brasileira sobre micorrizas, 8 , 2000; simpósio brasileiro de microbiologia do solo, 6, 2000; Reunião Brasileira de biologia do solo, 3, 2000. Resumos Expandidos ... sbcs/SBM: Santa Maria: 2000. (cd-rom).

BRASIL. Ministério da Agricultura: Departamento de Pesquisa Agropecuária. Levantamento de reconhecimento dos solos do Estado do Rio Grande do Sul. Recife: 1973. 431 p. (Boletim Técnico, 30).

CALDEIRA, M. V. W. Quantificação da biomassa e do conteúdo de nutrientes em diferentes procedências de acácia-negra (Acacia mearnsii De Wild.). Santa Maria: Universidade Federal de Santa Maria (UFSM), 1998. 96 p. (Dissertação - Mestrado em Engenharia Florestal).

CALDEIRA, M. V. W.; PEREIRA, J. C.; SCHUMACHER, M. V.; Comparação entre as concentração de nutrientes nas folhas e no folhedo em procedências de Acacia mearnsii De Wild. Rev. Árvore, Viçosa: v. 23, n. 4, p. 489-492. 1999c.

CALDEIRA, M. V. W.; RONDON NETO, R. M.; SCHUMACHER, M. V. Conteúdo e exportação de micronutrientes em acácia-negra (Acacia mearnsii De Wild.) procedência Batemans Bay (Austrália), plantada em Butiá RS: Brasil. Revista Árvore. Viçosa: 2002. (no prelo).

CALDEIRA, M. V. W.; SCHUMACHER, M. V.; PEREIRA, J. C.; DELLA-FLORA, J. B.; SANTOS, E. M. Concentração e redistribuição de nutrientes nas folhas e no folhedo em povoamento comercial de Acacia mearnsii De Wild. plantado no Rio Grande do Sul. Ciência Florestal. Santa Maria: v. 9, n. 1, p. 19-24. 1999b.

CALDEIRA, M. V. W.; SCHUMACHER, M. V.; SANTOS, E. M.; TEDESCO, N.; PEREIRA, J. C. Estimativa do conteúdo de nutrientes em um povoamento jovem de Acacia mearnsii De Wild. estabelecido na região sul do Brasil. Floresta. Curitiba: v. 29, n. 1 e 2, p. 53-65. 1999a.

CALDEIRA, M. V. W.; SCHUMACHER, M. V.; TEDESCO, N.; SANTOS, E. M. Ciclagem de nutrientes em Acacia mearnsii De Wild. V quantificação do conteúdo de nutrientes na biomassa aérea de Acacia mearnsii De Wild. procedência australiana. Ciência Rural. Santa Maria: v. 30, n. 6, p. 977-982. 2000.

DALlaGO, J. S. Utilização da cinza de biomassa de caldeira como fonte de nutrientes no crescimento de plantas de acácia-negra (Acacia mearnsii De Wild.). Santa Maria: Universidade Federal de Santa Maria (UFSM). 2000. 64 p. (Dissertação Mestrado em Engenharia Florestal).

EMPRESA BRASILEIRA DE PESQUISA AGROPECUÁRIA. Sistema brasileiro de 
classificação levantamento de solos: EMBRAPA/SNPS. Rio de Janeiro: 1999.212 p.

HIGA, A. R.; DEDECEK, R. A.; Santos, A. F.; STEIN, P. P.; SIMON, A. A. Desarrollo de sistemas de produccoón para acacia negra (Acacia mearnsii De Wild.). In: Congresso Latinoamericano iufro - $\mathrm{O}$ manejo sustentable de los recursos forestales, desafío del siglo XXI, 1., 1998. Valdivia: CD-Rom ... Valdivia: IUFRO, 1998.

IPAGRO - Instituto de Pesquisas Agronômicas. Atlas agroclimático do Estado do Rio Grande do Sul. Porto Alegre: 1989.3 v.

KOEHLER, C. W. Variação estacional da deposição de serapilheira e de nutrientes em povoamentos de Pinus taeda na região de Ponta Grossa - PR. Curitiba: Universidade Federal do Paraná, 1989. 148 p. (Tese Doutorado em Ciências Florestais).

KRAMER， P. J.; KOZLOWSKI， T. T. Physiology of wood plants. New York: Academic Press. 1979. 811p.

LIMA, W. P. Impacto ambiental do eucalipto. 2. ed. São Paulo: Editora da USP, 1996. p. 139-168.

MARSCHNER, H. Mineral nutrition of higher plants. San Diego: Academic Press Inc. $1997.889 \mathrm{p}$.

MORENO, J. A. Clima do Rio Grande do Sul. Porto Alegre: Secretaria da Agricultura, $1961.42 \mathrm{p}$.

PEREIRA, J. C.; CALDEIRA, M. V. W.; SCHUMACHER, M. V.; HOPPE, J. M.; SANTOS, E. M. Estimativa do conteúdo de nutrientes em um povoamento de Acacia mearnsii De Wild. no Rio Grande do Sul Brasil. Revista Árvore. Viçosa: v. 24, n. 2, p. 193-199, 2000.

PEREIRA, J. C.; CALDEIRA, M. V. W.; SCHUMACHER, M. V.; HOPPE, J. M.; SANTOS, E. M. Exportação de nutrientes em um povoamento de Acacia mearnsii De Wild. em idade de corte. In: Ciclo de Atualização Florestal do Cone-Sul, 1. Santa Maria - RS. Anais... Santa Maria: UFSM. 1999. p. 158164.
POGGIANI, F.; COUTO, H. T. Z.; SOITERFILHO, W. Biomass and nutrient estimates removal in short rotation intensively cultured plantations on Eucalyptus grandis. IPEF, Piracicaba: v. 23, p. 37-42. 1983.

REIS, M. G. F.; BARROS, N. F. Ciclagem de nutrientes em plantações de eucalipto. In: Barros, N.F.; Novais, R.F. (eds) RELAÇÃO SOLO-EUCALIPTO. Viçosa: Editora Folha de Viçosa, 1990. p. 265-301.

TEDESCO, M. J.; Gianello, C.; Bissani, C. A. et al. Análise de solos, plantas e outros materiais. Porto Alegre: UFRGS Departamento de Solos/Faculdade de Agronomia. 1995. 174p. (Boletim Técnico, 5).

VALERI, S. V.; REISSMANN, C. B.; SANTOS-FILHO, A. Exportação de nutrientes de povoamentos de Pinus taeda L. desbastados em diferentes idades. Floresta, Curitiba, v. 19, n. 1/2, p.62-68, 1989.

VAN DEN DRIESSCHE, R. Prediction of mineral status of trees by foliar analysis. The Botanical Review, New York: v. 40, p. $347-$ 394. 1984.

VEZZANI, F. M. Aspectos nutricionais de povoamentos puros e misto de Eucalyptus saligna (Smith) e de Acacia mearnsii De Wild. Porto Alegre: Universidade Federal do Rio Grande do Sul, 1997. 97 p. Dissertação (Mestrado em Ciência do Solo).

YONG, H. E.; CARPENTER, P. N. Sampling variation of nutrient element content within and between on trees of the same species. In: OSLO BIOMASS STUDIES, 1976, Oslo. Proceedings... Oslo: 1976. p. 75-90. 